\title{
Analisis Perbandingan Kadar Aspal Optimum (KAO) untuk Perbedaan Gradasi (BBA, FAA, dan BM)
}

\author{
Anwar Efendy ${ }^{1}$, Ervina Ahyudanari ${ }^{1, *}$ \\ Departemen Teknik Sipil, Institut Teknologi Sepuluh Nopember, Surabaya \\ Koresponden*, Email: ervina@ce.its.ac.id
}

\begin{tabular}{ll}
\hline & Info Artik \\
\hline Diajukan & 22 Januari 2019 \\
Diperbaiki & 29 Januari 2019
\end{tabular}

$\begin{array}{ll}\text { Diperbaiki } 29 \text { Januari } 2019 \\ \text { Disetujui } & 31 \text { Januari } 2019\end{array}$

Keywords: optimum bitumen content, aggregate gradation, $F A A, B M$, and $B B A$ Marshall test \begin{abstract}
Aggregate gradation is one of the important parts in a paved mixture. Mixed properties such as stability, stiffness, ease of work, permeability, durability, fatigue resistance, slip resistance, and water resistance are strongly influenced by aggregate gradations. There are 3 types of gradations used in this study, there are BBA gradation is open graded while FAA gradation and $B M$ gradation are dense graded. $B B A$ and $F A A$ are gradations used for airport pavement while $B M$ is a gradation used for road construction. In 2018, bitumen demand in Indonesia reaches 1.8 billion tons, but what can be fulfilled by local bitumen producers only reaches 344 million tons. PT. Pertamina (Persero) has only been able to fulfill $30 \%$ of domestic bitumen requirements. The remaining $70 \%$ of the bitumen is imported from Singapore because of the low supply of bitumen from domestic producers. The purpose in this study to determine comparision of the optimum bitumen content between BBA (Béton Bitumineux pour chausées Aéronautiques) gradation, FAA (Federal Aviation Administration) gradation and BM (Bina Marga 2010 revision 3) gradation. Between the 3 types of gradations, FAA gradation has the lowest Optimum Bitumen Content that is, FAA gradation 5,13\%, BM gradation 5,65\% and BBA gradation 6,1\%.
\end{abstract}

\begin{abstract}
Abstrak
Gradasi agregat adalah salah satu bagian penting dalam campuran beraspal. Sifat-sifat campuran seperti stabilitas, kekakuan, kemudahan kerja, permeabilitas, keawetan, ketahanan terhadap kelelahan, tahanan gelincir, dan ketahanan terhadap air sangat dipengaruhi oleh gradasi agregat. Ada 3 jenis gradasi yang digunakan dalam penelitian ini, yaitu gradasi BBA merupakan gradasi terbuka sedangkan gradasi FAA dan gradasi BM merupakan gradasi rapat. Gradasi BBA dan FAA merupakan gradasi yang digunakan untuk perkerasan bandara sementara BM adalah gradasi yang digunakan untuk pembangunan jalan. Pada tahun 2018, permintaan aspal di Indonesia mencapai 1,8 miliar ton, tetapi yang dapat dipenuhi oleh produsen aspal lokal hanya mencapai 344 juta ton. PT. Pertamina (Persero) hanya mampu memenuhi 30\% dari kebutuhan aspal dalam negeri. Sisanya $70 \%$ aspal diimpor dari Singapura karena pasokan aspal rendah dari produsen dalam negeri. Tujuan dalam penelitian ini untuk menentukan perbandingan dari kebutuhan kadar aspal optimum antara gradasi BBA (Beton Bitumineux pour chausées Aéronautiques), gradasi FAA (Federal Aviation Administration) dan gradasi BM (Bina Marga 2010 revisi 3). Dari ke 3 jenis gradasi tersebut, gradasi FAA yang memiliki Kadar Aspal Optimum terendah yaitu, 5,13\%, kemudian gradasi BM 5,65\% dan yang tertinggi gradasi BBA 6,1\%.
\end{abstract}

Kata kunci: kadar aspal optimum, gradasi agregat, FAA, BM, dan BBA, uji Marshall

Ada 3 jenis gradasi yang digunakan dalam penelitian ini,

\section{Pendahuluan}

Gradasi agregat adalah salah satu bagian penting dalam campuran beraspal. Sifat-sifat campuran seperti stabilitas, kekakuan, kemudahan kerja, permeabilitas, keawetan, ketahanan terhadap kelelahan, tahanan gelincir, dan ketahanan terhadap air sangat dipengaruhi oleh gradasi agregat [1]. Gradasi merupakan faktor yang paling mempengaruhi terhadap propertis Marshall campuran aspal beton, sehingga diperlukan untuk memilih gradasi agregat terbaik. Gradasi terbaik adalah gradasi agregat yang memberikan kepadatan tertinggi. Ketika partikel halus dikemas dengan benar di antara partikel kasar, yang mengurangi ruang kosong antara partikel disebut sebagai gradasi terbaik [2]. yaitu gradasi BBA yang merupakan gradasi terbuka sementara gradasi FAA dan gradasi BM merupakan gradasi rapat. Tetapi gradasi BBA dan FAA digunakan untuk perkerasan bandara sementara gradasi BM adalah gradasi digunakan untuk pembangunan konstruksi jalan, berikut penjelasan dari ketiga jenis gradasi:

- Gradasi BBA (Beton Bitumineux pour chausées Aéronautiques) merupakan standar perkerasan lapis permukaan lapangan terbang di Perancis dan telah digunakan di hampir semua perkerasan bandara di Perancis, termasuk dua landasan pacu di Paris Charles de Gaulle, dan Toulouse dengan track record lebih dari 18 tahun 
(Asosiasi Française de Normalisasi, 2008). Bahan material BBA sangat cocok karena pemeliharaan yang lebih mudah untuk masa yang akan datang, tidak memerlukan peralatan paving khusus atau pabrik pencampuran [3].

- Gradasi FAA (Federal Aviation Administration) merupakan peraturan gradasi yang dibuat oleh penerbangan sipil di Amerika Serikat. Sebagai bagian dari Departemen Perhubungan Amerika Serikat, lembaga ini bertanggung jawab untuk mengatur dan mengawasi penerbangan sipil di Amerika Serikat (fungsinya mirip dengan Direktorat Jenderal Perhubungan Udara di Indonesia). Pada tahun 1958 Federal Aviation Act menjadi dasar hukum bagi pembentukan nama "Federal Aviation Agency", dan menggunakan nama FAA saat ini pada tahun 1966 ketika FAA berlindung di bawah Dinas Perhubungan (Departemen Transportasi Amerika Serikat) (Federal Aviation Administration, 2007).

- Gradasi BM (Bina Marga) merupakan gradasi yang digunakan di Indonesia untuk pembangunan jalan dan jembatan yang sesuai dengan spesifikasi umum dari Direktorat Jenderal Bina Marga pada tahun 2010 (revisi 3) yang telah di pengaruh sejak 12 November 2014 (Bina Marga, 2014).

Aspal adalah zat perekat berwarna hitam atau gelap, yang dapat diperoleh dari alam atau sebagai akibat dari hasil produksi. Aspal juga didefinisikan sebagai bahan perekat dengan unsur-unsur utama dari aspal yang diperoleh dari residu dari penyulingan minyak bumi. Aspal merupakan material yang pada temperatur ruang berbentuk padat sampai agak padat, dan bersifat termoplastis. Jadi, aspal akan mencair jika dipanaskan sampai temperatur tertentu dan kembali membeku jika temperatur turun [4]. Ada 2 lokasi untuk produsen aspal di Indonesia, yaitu di Pulau Buton, Sulawesi Tenggara dan Wonokromo, Jawa Timur. Permintaan aspal untuk bahan konstruksi di Indonesia mencapai 1,3 juta ton per tahun [5].

Pada tahun 2018, permintaan aspal di Indonesia mencapai 1,8 miliar ton, tapi apa yang dapat dipenuhi oleh produsen aspal lokal hanya mencapai 344 juta ton. PT. Pertamina (Persero) hanya mampu memenuhi $30 \%$ dari kebutuhan aspal dalam negeri. Sisanya 70\% dari aspal diimpor dari Singapura karena pasokan aspal yang rendah dari produsen dalam negeri [6]. Selama periode 2015-2019 Kementerian PUPR merencanakan pembangunan jalan tol dengan total panjang $1.851 \mathrm{Km}$. Ini adalah faktor penyebab tingginya permintaan aspal di Indonesia. Oleh karena itu, penelitian ini bertujuan untuk menentukan kadar aspal optimum terendah berdasarkan 3 jenis gradasi yaitu BBA, FAA dan BM untuk mengatasi kekurangan pasokan aspal di Indonesia.

\section{Metode}

Metodologi penelitian ini dimulai dengan memiliki variasi gradasi. Variasi gradasi campuran tersebut dengan aspal untuk memiliki desain campuran perkerasan. Kinerja desain campuran diuji menggunakan uji Marshall. Gradasi penelitian ini menggunakan gradasi BBA, FAA dan BM. Pada agregat kasar menggunakan geopolimer agregat buatan $25 \%$ dan alami 75\%. Agregat buatan ini telah diuji dan diketahui bahwa karakteristik agregat buatan memiliki karakteristik yang baik [7]. Berikut ini spesifikasi standar dari 3 agregat tercantum pada Gambar 1, Gambar 2, dan Gambar 3.

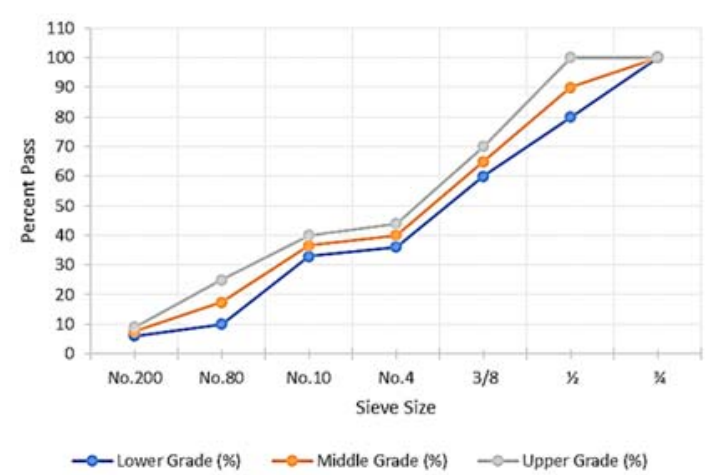

Gambar 1. Gradasi BBA

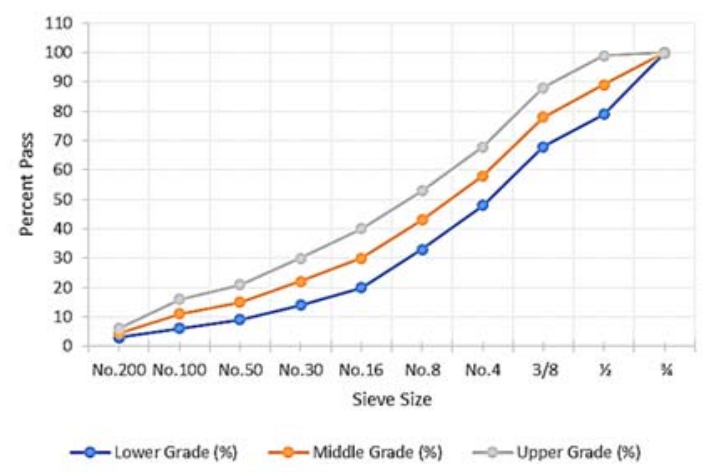

Gambar 2. Gradasi FAA

Gradasi FAA dan gradasi BM terlihat mirip satu sama lain. Perbedaan dari dua jenis gradasi ini pada ukuran sebagai berikut: di agregat halus gradasi FAA menggunakan ukuran saringan 100 tetapi gradasi BM menggunakan ukuran saringan 150. BBA gradasi memiliki ukuran yang mendominasi yaitu pada nomor saringan no. 10 dan no. 4. Ini akan menyebabkan gradasi BBA mampu mengurangi ketebalan lapisan sebesar $15 \%$. 


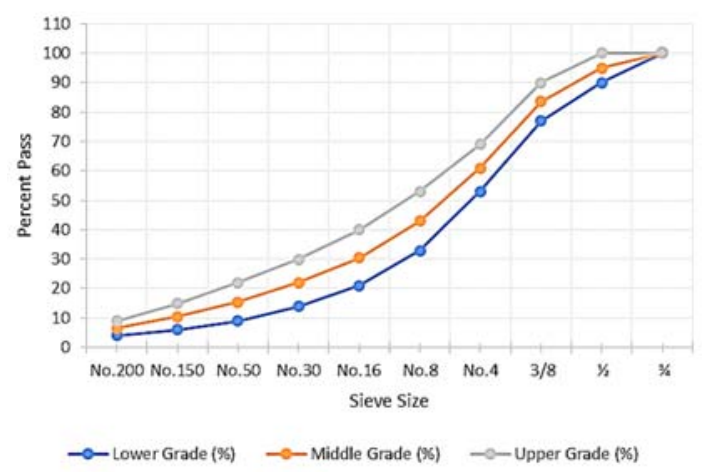

Gambar 3. Gradasi BM

\section{Uji Marshall}

Uji Marshall bertujuan untuk menentukan kadar aspal optimum, kemudian menentukan stabilitas dan flow campuran aspal dari hasil bacaan. Benda uji campuran aspal berdiameter 101,6 mm (4 inci) dan tinggi 76,2 $\mathrm{mm}$ (3 inci). Pemadatan untuk uji Marshall dilakukan dengan pukulan 75 kali per bidang dengan menggunakan pemadat. Setelah benda uji dipadatkan, kemudian disimpan pada suhu kamar selama 24 jam, maka benda ditimbang di udara, di air dan diketahui (SSD) kondisi jenuh permukaan yang kering untuk mendapatkan berat jenis bulk. Kemudian direndam pada suhu $60 \pm 1^{\circ} \mathrm{C}$ selama $30-40$ menit dan siap untuk melakukan pengujian stabilitas dan flow. Karakteristik campuran aspal yang sesuai parameter Marshall yaitu: kepadatan, VIM, VMA, VFA, stabilitas, flow dan Marshall Quotient. Berikut persyaratan Aspal Beton tercantum dalam Tabel 1 dan Tabel 2 di bawah ini:

Tabel 1. Persyaratan Aspal Beton untuk Bandara Perkerasan

\begin{tabular}{lc}
\hline \multicolumn{1}{c}{ Propertis Pengujian } & $\begin{array}{c}\text { Pavement Design for Aircraft } \\
\text { Gross Weights of 60.000 Lbs } \\
(27216 \mathrm{~kg}) \text { or more or Tire } \\
\text { pressures of } 100 \text { psi or more }\end{array}$ \\
\hline Number of blows & 75 \\
Stability, pounds (Newtons) & $2150(9560)$ \\
minimum & \\
Flow, 0.01 inch. (0.25 mm) & $10-16$ \\
Target air voids (percent) & 3.5 \\
Percent VMA (minimum) & $15 \%$ \\
\hline
\end{tabular}

Sumber: Federal Aviation Administration, 2014

\section{Penentuan Kadar Aspal Optimum}

Hal ini dilakukan dengan menggunakan metode barchart, di mana bar chart yang dibuat menunjukkan kisaran tingkat aspal yang memenuhi setiap karakteristik Marshall sesuai dengan spesifikasi. Kadar aspal optimum ditentukan oleh kadar aspal yang memenuhi semua spesifikasi karakteristik Marshall [8].

Tabel 2. Persyaratan Aspal Beton untuk Perkerasan Jalan

\begin{tabular}{lc}
\multicolumn{1}{c}{ Propertis Pengujian } & Persyaratan \\
\hline Stability $(\mathrm{kg})$ & $\min .800$ \\
Flow $(\mathrm{mm})$ & $2-4$ \\
MQ $(\mathrm{kg} / \mathrm{mm})$ & $\min .250$ \\
VIM $(\%)$ & $3-5$ \\
VMA $(\%)$ & $\min .15$ \\
VFB $(\%)$ & $\min .65$ \\
\hline
\end{tabular}

Sumber: Bina Marga, 2010

\section{Hasil dan Pembahasan}

Karakteristik Campuran Aspal

Dari tes Marshall (diketahui dua data, yaitu nilai stabilitas dan flow). Untuk mendapatkan nilai stabilitas yang tepat, maka dari bacaan alat perlu dikalibrasi terlebih dahulu, maka nilai kalibrasi dikalikan dengan hasil angka koreksi diperoleh berdasarkan ketinggian benda uji. Hasil stabilitas nilai dibagi dengan nilai flow disebut Marshall Quotient. Berikut Hasil Marshall Properti yang tercantum dalam Tabel 3, Tabel 4 dan Tabel 5.

Tabel 3. Hasil Properti Marshall (BBA)

\begin{tabular}{ccccccc}
\hline \multirow{2}{*}{$\begin{array}{c}\text { Propertis } \\
\text { Pengujian }\end{array}$} & Persyaratan & 5 & 5,5 & 6 & 6,5 & 7 \\
\hline Stability & $2150 \mathrm{lbs}$ & 3967 & 4750 & 4450 & 4193 & 3953 \\
Flow & $10-16 \mathrm{inch}$ & 14,7 & 14,8 & 14,3 & 14,4 & 16,3 \\
Target Air & 3.5 & 7,11 & 6 & 3,93 & 1,94 & 0,38 \\
Voids (\%) & & 16,25 & 16,27 & 15,45 & 14,72 & 14,4 \\
VMA (\%) & $15 \%$ & & & & & \\
\hline
\end{tabular}

Berdasarkan Hasil Propertis Marshall di atas, dapat ditentukan kadar aspal optimum dari gradasi BBA menggunakan metode bar-chart tercantum dalam Gambar 4.

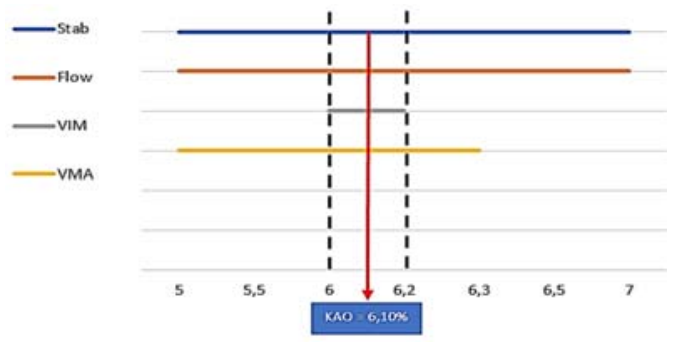

Gambar 4. Kadar Aspal Optimum (BBA)

Berdasarkan Hasil Propertis Marshall di atas, dapat ditentukan kadar aspal optimum dari gradasi BM menggunakan metode bar-chart tercantum dalam Gambar 5. 
Tabel 4. Hasil Properti Marshall (BM)

\begin{tabular}{|c|c|c|c|c|}
\hline \multirow{2}{*}{$\begin{array}{l}\text { Propertis } \\
\text { Pengujian }\end{array}$} & \multirow{2}{*}{ Persyaratan } & \multicolumn{3}{|c|}{ Kadar Aspal (\%) } \\
\hline & & 5 & 6 & 7 \\
\hline Stability $(\mathrm{kg})$ & $\min .800$ & 1547,6 & 1536,2 & 1625,9 \\
\hline Flow (mm) & $2-4$ & 2,6 & 3,8 & 5,5 \\
\hline $\mathrm{MQ}(\mathrm{kg} / \mathrm{mm})$ & $\min .250$ & 603,29 & 416,11 & 320,71 \\
\hline VIM (\%) & $3-5$ & 6,3304 & 3,0221 & 1,7313 \\
\hline VMA (\%) & $\min .15$ & 17,017 & 16,122 & 17,015 \\
\hline VFB (\%) & $\min .65$ & 63,035 & 81,323 & 89,835 \\
\hline
\end{tabular}

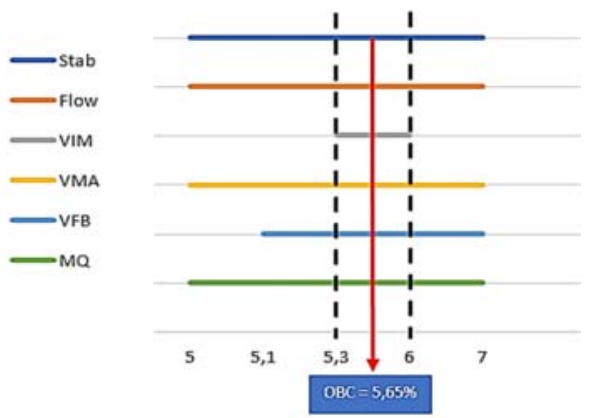

Gambar 5. Optimum Bitumen Content (BM)

Tabel 5. Hasil Properti Marshall (FAA)

\begin{tabular}{ccccccc}
\hline \multirow{2}{*}{$\begin{array}{c}\text { Propertis } \\
\text { Pengujian }\end{array}$} & Persyaratan & \multicolumn{5}{c}{ Kadar Aspal (\%) } \\
& & 4.50 & 5.00 & 5.50 & 6.00 & 6.50 \\
\hline Stabilitas & $2150 \mathrm{lbs}$ & 3128 & 3797 & 3917 & 3969 & 3932 \\
Flow & $\begin{array}{c}10-16 \\
\text { inch }\end{array}$ & 12.3 & 12 & 11.7 & 12.9 & 13.7 \\
Target Air & 3.5 & 5.80 & 3.82 & 2.89 & 1.06 & 0.77 \\
Voids (\%) & & & & & \\
VMA (\%) & $15 \%$ & 18.50 & 17.74 & 17.89 & 17.30 & 18.01 \\
\hline
\end{tabular}

Berdasarkan Hasil Propertis Marshall pada Tabel 5, dapat ditentukan kadar aspal optimum dari gradasi FAA menggunakan metode bar-chart tercantum dalam Gambar 6.

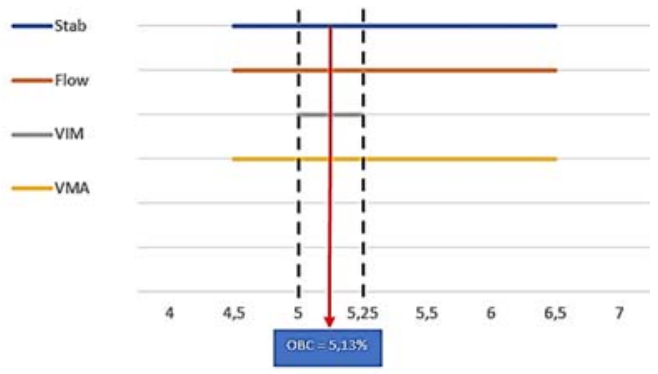

Gambar 6. Kadar Aspal Optimum (FAA)

Dari tiga jenis gradasi dapat mempengaruhi kadar aspal optimum. Tetapi, di setiap jenis gradasi memiliki kelebihan dan kekurangan. Seperti gradasi FAA dan gradasi BBA.
Gradasi FAA adalah campuran bergradasi rapat berkinerja sangat baik termasuk daya tahan dan integritas tetapi membutuhkan pemeliharaan yang lebih sering untuk mempertahankan tingkat ketahanan selip yang memadai [9]. Sementara Gradasi BBA bersifat terbuka dan BBA memiliki keunggulan praktis karena dapat juga ditempatkan sebagai binder course/lapis pengikat. Karena karakteristik gesekan basah yang baik, ini memungkinkan pesawat untuk mendarat di bagian jalur pengikat BBA yang dapat digunakan 'terbuka' atau sebagai permukaan tempat berjalan sementara selama pekerjaan perbaikan landasan pacu [10].

Analisis Data Pengujian Marshall

Kadar Aspal Optimum dan stabilitas ditunjukkan pada Gambar 7.

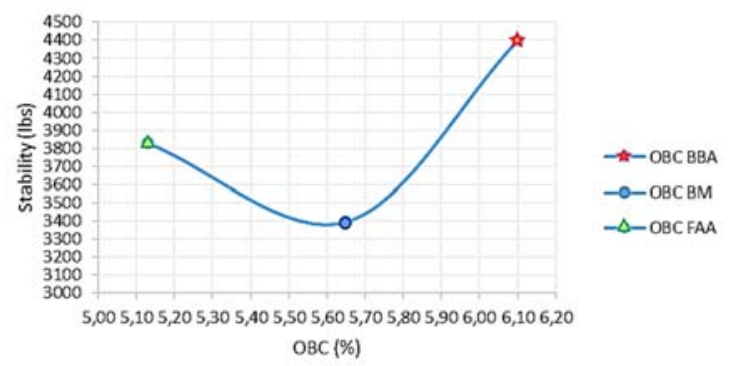

Gambar 7. KAO vs Stabilitas

Berdasarkan Gambar 7 nilai stabilitas tertinggi adalah gradasi BBA (4398,6 lbs) dengan kadar aspal optimum $6,10 \%$, sedangkan nilai stabilitas terendah adalah gradasi BM (3395,5 lbs) dengan kadar aspal optimum 5,65\% dan nilai tengah stabilitas adalah gradasi FAA (3828,2 lbs) dengan kadar aspal optimum 5,13\% yang diperoleh menggunakan metode interpolasi. Hal ini terjadi karena gradasi dan butiran agregat yang digunakan campuran gradasi terbuka (BBA) memiliki lebih besar nilai fraksi kasar. Kadar Aspal Optimum dan flow ditunjukkan pada Gambar 8.

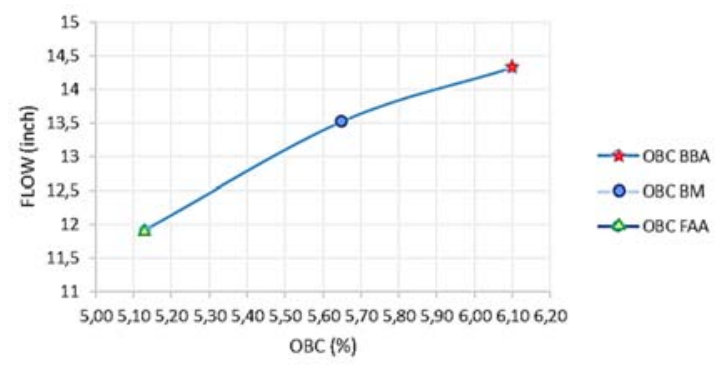

Gambar 8. Kadar Aspal Optimum vs Flow 
Berdasarkan Gambar 8 meningkatnya nilai kadar aspal menyebabkan nilai flow juga meningkat, campuran menjadi semakin plastik. Nilai flow tertinggi yaitu gradasi BBA (14,32 inci) dengan kadar aspal optimum $6.10 \%$, sedangkan nilai flow terendah yaitu gradasi FAA (11,92 inci) dengan kadar aspal optimum 5,13\% dan nilai tengah dari flow adalah gradasi BM (13,52 inci) dengan kadar aspal optimum 5,65\% yang diperoleh menggunakan metode interpolasi. Kadar Aspal Optimum dan Target Air Voids ditunjukkan pada Gambar 9.

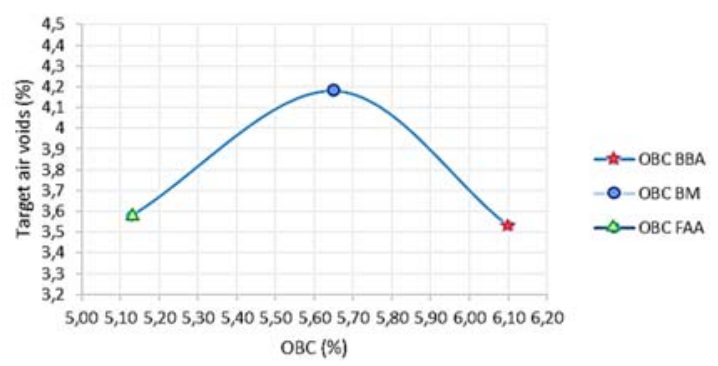

Gambar 9. Kadar Aspal Optimum vs Target Air Void

Berdasarkan Gambar 9 nilai tertinggi target air void adalah gradasi BM (4,18\%) dengan kadar aspal optimum $5,65 \%$, sedangkan nilai yang rendah dari target air void yaitu gradasi BBA $(3,53 \%)$ dengan kadar aspal optimum 6,10\% dan nilai tengah dari target air void yaitu gradasi FAA (3,58\%) dengan kadar aspal optimum 5,13\% yang diperoleh menggunakan metode interpolasi. Semakin meningkat jumlah kadar aspal, maka aspal akan mengisi rongga yang tersisa sehingga jumlah void menurun dengan meningkatnya kadar aspal. Kadar Aspal Optimum dan VMA ditunjukkan pada

\section{Gambar 10.}

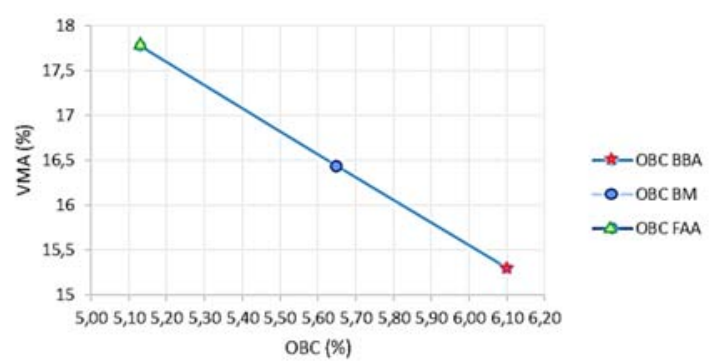

Gambar 10. Kadar Aspal Optimum vs VMA

Berdasarkan Gambar 10 meningkatnya kadar aspal, nilai VMA akan cenderung menurun hingga mencapai titik minimum dan akan meningkat lagi sesuai dengan penambahan kadar aspal yang lebih tinggi. Hal ini karena aspal akan mengisi kekosongan antara agregat sampai kekosongan tidak bisa diisi oleh aspal, dalam hal ini nilai VMA menjadi minimum. Nilai VMA tertinggi yaitu gradasi FAA (17,78\%) dengan kadar aspal optimum 5,13\%, sedangkan nilai VMA yang rendah adalah gradasi BBA $(15,3 \%)$ dengan kadar aspal optimum $6,10 \%$ dan nilai tengah VMA adalah gradasi BM $(16,44 \%)$ dengan kadar aspal optimum 5,65\% yang diperoleh menggunakan metode interpolasi.

\section{Simpulan}

Berdasarkan hasil pengujian di laboratorium dan analisis data, maka dapat disimpulkan bahwa kadar aspal optimum dari tiga jenis gradasi yaitu gradasi FAA 5,13\%, gradasi BM $5,65 \%$ dan gradasi BBA $6,1 \%$.

Diantara ke-3 jenis gradasi, gradasi FAA memiliki nilai kadar aspal optimum terendah sebesar 5,13\%. Jadi, dapat disimpulkan gradasi FAA mampu mengurangi kebutuhan prnggunaan aspal yang meningkat di Indonesia.

Nilai stabilitas tertinggi pada gradasi BBA sebesar (4398,6 lbs) dengan kadar aspal optimum 6,10\%. Hal ini disebabkan karena gradasi dan butiran agregat yang digunakan campuran gradasi terbuka (BBA) memiliki lebih besar nilai fraksi kasar.

Nilai flow tertinggi gradasi BBA (14,32 inci) dengan kadar aspal optimum $6.10 \%$, meningkatnya kadar aspal maka nilai flow juga meningkat, hal ini disebabkan oleh meningkatnya jumlah kadar aspal dan campuran menjadi semakin plastik.

Nilai terendah pada target air void yaitu gradasi BBA sebesar $(3,53 \%)$ dengan kadar aspal optimum $6,10 \%$. Semakin meningkat kadar aspal maka aspal akan mengisi rongga yang tersisa sehingga jumlah rongga menurun dengan terisinya kadar aspal.

Nilai terendah dari VMA adalah gradasi BBA sebesar (15,3\%) dengan kadar aspal optimum 6,10\%. Meningkatnya kadar aspal, maka nilai VMA akan cenderung menurun hingga mencapai titik minimum dan akan meningkat lagi sesuai dengan penambahan kadar aspal yang lebih tinggi. Hal ini karena aspal akan mengisi kekosongan antara agregat sampai kekosongan tidak bisa diisi oleh aspal, dalam hal ini nilai VMA menjadi minimum.

\section{Daftar Pustaka}

[1] T. W. Roberts, F.L., Kandhal, P.S., Brown, E.R., Lee, D.Y., dan Kennedy, Hot Mix Asphalt Materials, Mixture Design, and Construction, First. Lanham: NAPA Education Foundation, 1991.

[2] R. Maharjan, G. Bir, and S. Tamrakar, "Effect of Aggregate Gradation Variation on the Marshall Mix Properties of Asphalt Concrete," vol. 8914, pp. 213219, 2017.

[3] I. Widyatmoko, B. Hakim, C. Fergusson, and J. Richardson, "The Use of French Airfield Asphalt 
Concrete in the UK," Eur. Road Rev., no. 13, 2008.

[4] S. Sukirman, Beton Aspal Campuran Panas. Jakarta: Granit, 2003.

[5] D. Energi, "Aspal Pertamina Baru Bisa Penuhi 30\% Kebutuhan di Dalam Negeri," 2017. http://www.dunia-energi.com/aspal-pertamina-barubisa-penuhi-30-kebutuhan-di-dalam-negeri/ (diakses tanggal, 22 Desember, 2018)

[6] F. J. Kuwado, "Kementrian PUPR Lebih Banyak Gunakan Aspal Impor, Ini Penjelasan Basuki," 04Sep-2018.

https://nasional.kompas.com/read/2018/09/04/18012 801/kementerian-pupr-lebih-banyak-gunakan-aspalimpor-ini-penjelasan-menteri (diakses tanggal, 22 Desember, 2018)

[7] I. D. A. Karyawan, E. Ahyudanari, and J. J. Ekaputri, "Potential Use of Fly Ash Base-Geopolymeras Aggregate Substitution in Asphalt Concrete Mixtures," Int. J. Eng. Technol., vol. 9, no. 5, pp. 3744-3752, 2017.

[8] A. Thanaya, "Studi Karakteristik Campuran Aspal Beton Lapis Aus ( AC-WC ) Menggunakan Aspal Penetrasi $60 / 70$ dengan Penambahan Lateks Material dan Metode," vol. 22, no. 2, pp. 77-86, 2016.

[9] P. B. Joubert, L. Gounder, and S. van Wy, "Asphalt Trial Sections in The Touch Down Zone on Johannesburg International Airport," Proc. 8th Conf. Asph. Pavements South. Africa, no. September, pp. 31-42, 2004.

[10] B. Iswandaru et al., "French Airfield Asphalt Concrete at Manchester Airport French Airfield Asphalt Concrete at Manchester Airport," no. February 2011, 2015. 